\title{
On the Introduction of Culture into College English Teaching
}

\author{
Wenquan $\mathrm{Wu}$ \\ Foreign Languages College, Qingdao University of Science and Technology, Qingdao, China \\ Email: wuwenquan@qust.edu.cn
}

\begin{abstract}
This paper discusses the present problem in college English teaching from the constructive perspective. It highlights the necessity to introduce culture into college English teaching and probes further into the problems of college English teaching and approaches of culture introduction. The main purpose is to tackle the practical problem in college English teaching and promote teaching efficiency so as to develop the students' cross-culture communicative ability.
\end{abstract}

Index Terms - constructivism, culture introduction, cross-culture communicative ability

\section{INTRODUCTION}

Being a teacher of college English for many years, I am often bewildered by the fact that so many Chinese students can not communicate well in English even if they score high in English and have already passed CET-4 or CET-6. It is out of doubt that these Chinese students have good commands of English vocabulary and grammar. So what is the reason why they succeed in learning English yet fail in communicating in English?

Then a survey of students of Qingdao University of Science and Technology concerning the factors that interfere with their cross-culture communicative ability is made here. The poll shows that among all the factors, culture plays a vital part in their cross-culture communicative abilities. That is to say, besides the traditional teaching of basic skills such as vocabulary and grammar, we should also attach great importance to the introduction of culture.

As the major concern of applied linguistics, language teaching and language learning have been the focuses of linguists as well as language teachers. And an increasing number of language teaching methodologies and theories were introduced and discussed worldwide. Among them, there are prominent ones such as Constructivism, which probe a better way of thinking for us. We can explain the importance of culture introduction from the constructive perspective.

This paper looks back on the theories of constructivism. And then goes on to discuss the introduction of culture into college English, including its contents and approaches. The purpose is to tackle the problems in cross-culture communication so as to facilitate the college English teaching. And our final goal is to help language learner attain high English proficiency.

\section{THE THEORY OF CONSTRUCTIVISM}

\section{A. An Overview}

1. Constructivism

The verb "to construct" comes from the Latin Construere, which means to arrange or give structure. Ongoing structuring (organizing) processes are the conceptual heart of constructivism.

The words "construct" and "construction" have been in use for centuries, of course. But "constructivism" is a relatively new word. Yet it is appearing with an accelerating frequency in the titles of books and articles in psychology.

Constructivism is based on the idea that, unlike a computer disk or an empty container, students do not wait passively to be filled up with knowledge. Rather, students actively build, or construct, their own knowledge. Teachers cannot entirely control their students' learning; expert teachers can do much to facilitate students' own active learning processes. (Cobb, 2000)

Constructivism is a philosophy of learning founded on the premise that, by reflecting on our experiences, we construct our own understanding of the world we live in. Each of us generates our own "rules" and "mental models", which we use to make sense of our experiences. Learning, therefore, is simply the process of adjusting our mental models to accommodate new experiences.

The essence of constructivism is the idea that learners must individually discover and transform complex information if they are to make it their own. Constructivists' theory sees learners as constantly checking new information against old rules and then revising the rules when they on longer work. This view has profound implications for teaching, as it suggests a far more active role for students in their own learning than is typical in the great majority of classrooms.

2. Constructivist Theory

Formalization of the theory of constructivism is generally attributed to Jean Piaget (1950), who articulated mechanisms by which knowledge is internalized by learners. He suggested that through processes of accommodation 
and assimilation, individuals construct new knowledge from their experiences. When individuals assimilate, they incorporate the new experience into an already existing framework without changing that framework. This may occur when individuals' experiences are aligned with their internal representations of the world, but may also occur as a failure to change a faulty understanding; for example, they may not notice events, may misunderstand input from others, or may decide that an event is a fluke and is therefore unimportant as information about the world. In contrast, when individuals' experiences contradict their internal representations, they may change their perceptions of the experiences to fit their internal representations. According to the theory, accommodation is the process of reframing one's mental representation of the external world to fit new experiences. Accommodation can be understood as the mechanism by which failure leads to learning: when we act on the expectation that the world operates in one way and it violates our expectations, we often fail, but by accommodating this new experience and reframing our model of the way the world works, we learn from the experience of failure, or others' failure.

It is important to note that constructivism is not a particular pedagogy. In fact, constructivism is a theory describing how learning happens, regardless of whether learners are using their experiences to understand a lecture or following the instructions for building a model airplane. In both cases, the theory of constructivism suggests that learners construct knowledge out of their experiences.

\section{B. Main Ideas about Learning}

Constructivist ideas about learning are based on the idea that learners must build their own knowledge-it cannot be given to them - and that new knowledge builds on current knowledge.

Learning is a search for meaning. Therefore, learning must start with the issues around which students are actively trying to construct meaning. Meaning requires understanding wholes as well as parts. And parts must be understood in the context of wholes. Therefore, the learning process focuses on primary concepts, not isolated facts. Learning should be whole, authentic, and real. Meaning is constructed as learners interact in meaningful ways with the world around them. Students are more likely to learn if they are engaged in meaningful activities, such as operating a class "store" or "bank" or writing and editing a class newspaper. Whole activities, as opposed to isolated skill exercises, authentic activities which are inherently interesting and meaningful to students, and real activities that result in something other than a grade on a text or a "Great, you did well" from the computer lesson software, are emphasized in constructivism classroom. The purpose of learning is for an individual to construct his or her own meaning, not just memorize the "right" answers and regurgitate someone else's meaning. Since education is inherently interdisciplinary, the only valuable way to measure learning is to make the assessment part of the learning process, ensuring it provides students with information on the quality of their learning.

To summarize, learning emphasizes the process and not the product. How one arrives at a particular answer, and not the retrieval of an "objectively true solution", is what is important. Learning is a process of constructing meaningful representations, of making sense of one's experiential world. Students' errors are seen in a positive light and as a means of gaining insight into how they are organizing their experiential world.

\section{Main Ideas about Teaching}

1. Teacher should create real world environments that employ the context in which learning is relevant.

2. We should focus on realistic approaches to solving real-world problems.

3. The instructor is a coach and analyzer or the strategies used to solve these problems.

4. Teacher should stress conceptual interrelatedness, providing multiple representations or perspectives on the content.

5. Instructional goals and objectives should be negotiated and not imposed.

6. Evaluation should serve as self-analysis tool.

7. Provide tools and environments that help learners interpret the multiple perspectives of the world.

8. Learning should be internally controlled and mediated by the learner.

\section{The Importance of the Background and Culture of the Learner}

Constructivism encourages the learner to arrive at his or her version of the truth, influenced by his or her background, culture or embedded worldview. Historical developments and symbol systems, such as language, logic, and mathematical systems, are inherited by the learner as a member of a particular culture and these are learned throughout the learner's life. This also stresses the importance of the nature of the learner's social interaction with knowledgeable members of the society. Without the social interaction with other more knowledgeable people, it is impossible to acquire social meaning of important symbol systems and learn how to utilize them. Young children develop their thinking abilities by interacting with other children, adults and the physical world. From the social constructivist viewpoint, it is thus important to take into account the background and culture of the learner throughout the learning process, as this background also helps to shape the knowledge and truth that the learner creates, discovers and attains in the learning process. (Wertsch 1997)

\section{The Introduction of Culture into College English Teaching}




\section{A. Culture}

The word culture, from the Latin colo, -ere, with its root meaning "to cultivate", generally refers to patterns of human activity and the symbolic structures that give such activity significance. Different definitions of "culture" reflect different theoretical bases for understanding, or criteria for evaluating, human activity. Anthropologists most commonly use the term "culture" to refer to the universal human capacity to classify, codify and communicate their experiences symbolically.

\section{B. The Necessity of Culture Introduction in College English}

First of all, it is necessary that culture is to be introduced in college language teaching. On one hand, the communication of language must be based on the communication of culture. We can learn from the famous American linguist Edward Sapir (1921) that it is believed that language is supposed to be rooted in a certain environment, and it can not exist without culture. Sapir holds that culture can be defined as what the society thought and done, i. e. the collection of what people have thought, have said (verbal and non-verbal), have done and have perceived while language can be defined as the way the thought are expressed. And we also have the sociolinguists Richard Hudson (1980) who also believe that in many aspects language is contained in culture so a language in certain society is a part of its culture and the relation of langue and culture is that of a part and a whole. So we can draw the conclusion that the language and culture are inseparable. Language is an active part of culture and culture is the carrier of language.

On the other had, the ultimate goal of college English teaching is to cultivate the cross-culture communicative ability of the students. Just as the College English Syllable (1999) has stated that besides being a tool of communicating information, English also helps learners broaden new horizon and have insight into other culture so as to improve their cultural attainment. Enlightened by College English Syllable, we are to combine the teaching of college English with the teaching of culture closely in order to make them intermingle and advance with each other. On occasion of cross-culture communication, it is far from enough to just know the pronunciation, vocabulary and grammar of the target language. A good acquaintance of the custom, value, thought of its society, even if the non-verbal language of its people is crucial. Otherwise, there will be barriers in cross-culture communication. All in all, culture introduction is essential to college English teaching.

\section{Some Problems of Cross-culture Communication in QUST}

So we college English teachers have the duty to introduce culture into language learning and teaching. The followings are the problems I have found out from the survey carried out in Qingdao University of Science and Technology.

1. Lack of the Background Knowledge of the Words and Phrases

Above all, the cultural implication of words is of vital importance to college English learning and teaching. Since college students have already learnt English for many years, they have mastered a lot of words and phrases, which contribute to their successful communication. And the survey shows that most misusage of words occurs when they lack the background knowledge of the words and phrases. For example (Yanchang Deng \& Ruiqing Liu, 1989), Red Bean is a kind of common plant. In Chinese, it is the symbol of keen missing of the lovers. Yet, in English it has something to do with the story of Essau in Bible. So this word has absolutely different implication in different languages. If the students don't have the background knowledge of it, it is inevitable that misunderstanding and failure in cross-culture communication will occur.

And also, we have the phrase Paint the Lily in English. Some Chinese college students will just understand it word by word, that is, to paint the picture of lily. They are not aware of the culture implication of the word Lily, which stands for purity. So it is unnecessary to paint the lily, because it is so perfect that it needs nothing more. The counterpart of this phrase in Chinese is HuaSheTianZu, which comes from a Chinese fable and means make an unnecessary move (Yanchang Deng \& Ruiqing Liu, 1989). So we can draw the conclusion that the introduction of culture is essential to the learning and teaching of college English. If the college students do not have insight into the English culture, it is impossible for them to understand the implication of the words and phrases, let alone communicate adequately in English.

2. Inadequate Usage of Daily expressions

A good acquaintance of the expression of daily use will play a better role in cross-culture communication, which mainly including daily greetings and taboos. Though there are some similar daily expressions in both languages, there are still different ones. For example, upon receiving apology from others, it is OK for us to say Meiguanxi in Chinese, which also means it doesn't matter. Yet the proper way to answer the apology it is to say "That's all right." or "No problem." (Yunxin Jia, 1997)

And also, there are taboos in every language. It is quiet common for Chinese to talk about ages while it will cause unpleasant feelings for the foreigners. This mainly originates from the difference of the custom of the target language. Besides ages, the college students should also be fully aware of some taboos such as marriage, income, religion and politics.

3. Ignorance of the Non-verbal Language

Non-verbal language is also called body language, which includes gesture, motion, tone, silence, etc. There are different body languages in different cultures. And it attributes to the deeply-rooted customs and norms of the society. 
For example, it is quite acceptable for girl students to walk hand in hand in China, while it will cause some misunderstanding for foreigners. So besides a good command of words and daily expressions, we should also get the college students aquatinted with the non-verbal language of the target language, which also plays a vital role in the cross-culture communication.

4. Neglect of Different Values

Furthermore, there is something invisible yet indispensible in cross-culture communication. It is different values that are underlying the rules of all human activities, including communication. Actually, what we said and what we do depend heavily on the value system we share. So it is easier for us to understand the difficulty college students encountered in cross-culture communication. The differences in value and culture are reflected via language. Take the example of people's attitude toward time in America and China. Americans value time so much that they believe no one stand still and time is precious. Yet we Chinese used to take a leisurely attitude toward time. So when it comes to an appointment, it is the America who tends to be more punctual. And a lot of inconveniences originated from the neglect of different values of different cultures. We can learn that value is the core of the culture. Only when we have a good insight of the value and culture of the target language, can we avoid the failure in cross-culture communication.

\section{Approaches of Improving Cross-culture Communicative Ability}

\section{Specialized Course on Culture Introduction}

Nowadays more and more universities in China have been aware of the importance of the culture introduction into college English. And they are gonging out of their way to improve the Cross-culture communicative abilities of their students. Most of them take actions on their teaching curriculum and make an advance reform. Specialized courses on culture introduction are adopted nationwide. So besides the basic knowledge about words and grammar, students also have access to a variety of cultures, which enriches their knowledge and inspires them to communicate more. Thus, their Cross-culture communicative ability will gradually be improved. So this approach is strongly recommended by the author of this paper.

2. Culture Introduction Integrated with College English Teaching

And of course, it is indispensible to integrate college English with culture introduction. A good introduction of culture will help students understand the teaching material better, and motivate them to work harder. For example, when we are working on the text Lessons from Tomas Jefferson, it is necessary for us to know the relevant knowledge about the great man Tomas Jefferson, his age and his great deed. And then we can make a comparison with the Chinese great leaders. It will arouse the interest of the students and inspire them, encouraging them to learn a good lesson from the noble man Tomas Jefferson. Thus, it will be an easier and much more interesting task for the college students to learn English.

3. Create Meaningful Activities

As mentioned above, the background and culture of the target language is essential to English learning and teaching. A learner is a member of a particular culture. So it is important for the learners to interact with knowledgeable in the society or the authentic context. Without the social interaction with other more knowledgeable people, it is impossible to acquire social meaning of important symbol systems and learn how to utilize them. Yet this real world environment that employs the context in which learning is relevant is rare in China. So it is the teacher's duty to create meaningful activities both in class and after class. There will be meaningful activities such as role-play, situation talk and classroom presentation. And the English parties and evenings sound a good idea for the college students too. The more they get involved in the real world environment, the better and faster they will master the cross-culture communicative ability.

\section{E. The Role of the Instructor as Facilitators}

According to the constructivist approach, instructors have to adapt to the role of facilitators and not teacher (Bauersfeld, 1995). Whereas a teacher gives a lecture that covers the subject matter, a facilitator helps the learner to get to his or her own understanding of the content. In the former scenario the learner plays a passive role and in the latter scenario the learner plays an active role in the learning process. The emphasis thus turns away from the instructor and the content, and towards the learner (Gamoran, Secada, \& Marrett, 1998). This dramatic change of role implies that a facilitator needs to display a totally different set of skills than a teacher (Brownstein 2001). A teacher tells, a facilitator asks; a teacher lectures from the front, a facilitator supports from the back; a teacher gives answers according to a set curriculum, a facilitator provides guidelines and creates the environment for the learner to arrive at his or her own conclusions; a teacher mostly gives a monologue, a facilitator is in continuous dialogue with the learners. A facilitator should also be able to adapt the learning experience 'in mid-air' by taking the initiative to steer the learning experience to where the learners want to create value.

The learning environment should also be designed to support and challenge the learner's thinking (Di Vesta \& Thompson, 1970). While it is advocated to give the learner ownership of the problem and solution process, it is not the case that any activity or any solution is adequate. The critical goal is to support the learner in becoming an effective thinker. This can be achieved by assuming multiple roles, such as consultant and coach.

\section{CONCLUSION}


To summarize, this research studies the introduction of culture into college English teaching on the basis of constructivism theory. And the problems and approached were analyzed to promote the learner's cross-culture communicative ability. Due to the limited knowledge of the author and the scale of the subject, there is much more room for improvement. Nevertheless, the study and analysis proved constructivism theory to be of great value to both language learner and teacher, and the approached discussed will have a large impact on both languages learning and teaching. The author of the paper deeply hopes this thesis would be of value for further exploration in the field of language learning and teaching.

\section{REFERENCES}

[1] Cobb, P., Yackel, E., \& McClain, K. (Eds.) (2000). Communicating and symbolizing in mathematics: Perspectives on discourse, tools, and instructional design. Mahwah, NJ: Lawrence Erlbaum Associates.

[2] Jean Piaget (1950). The Psychology of Intelligence. New York: Routledge.

[3] Wertsch, J.V (1997). Vygotsky and the formation of the mind. Cambridge: Cambridge University Press.

[4] Edward Sapir (1921). Language: An introduction to the study of speech. New York: Harcourt, Brace and company.

[5] Richard Hudson (1980) Sociolinguistics. Cambridge [Eng.] ; New York : Cambridge University Press.

[6] Committee of College English Syllable (1999). College English Syllable (revised). Shanghai: Shanghai Foreign Language Education Press.

[7] Yanchang Deng \& Ruiqing Liu. (1989). Language and Culture. Beijing: Foreign Language Teaching and Research Press.

[8] Yunxin Jia. (1997). Cross-culture communication. Shanghai: Shanghai Foreign Language Education Press.

[9] Bauersfeld H. (1995). "Structuring the structures". In L. P. Steffe \& J. Gale (Eds.), Constructivism and education. Hillsdale, NJ: Lawrence Erlbaum Associates.

[10] Gamoran, A, Secada \& W.G., Marrett, C.A (1998). The organizational context of teaching and learning: changing theoretical perspectives, in Hallinan, M.T (Eds), Handbook of the Sociology of Education. New York: Springer Science + Business Media

[11] Samuel C. Brownstein. (1984). Vocabulary builder. Hauppauge, New York: Barron's Educational Series.

[12] Francis J. Di Vesta \& George G. Thompson. (1970). Educational psychology: instruction and behavioral change. New York: Appleton-Century-Crofts

Wenquan Wu was born in Qingdao, 29th, Jan., 1976. and obtained Master of Arts in linguistics from China Ocean University in Qingdao in 2006.

She works as a TUTOR in Qindao University of Science and Technology in Qingdao from 1998 till now. 